\title{
EXAMINING THE ROLE OF THE NITRIC OXID SYSTEM AS THE ESSENTIAL PATHOGENETIC LINK IN STEVENS-JOHNSON SYNDROME
}

DOI: 10.36740/WLek202009202

\author{
Natalya V. Ivanyushko - Nazarko, Orysya 0. Syzon, Svitlana V. Volbyn, Tetyana I. Rudnyk, Marianna 0. Dashko \\ DANYLO HALYTSKY LVIV NATIONAL MEDICAL UNIVERSITY, LVIV, UKRAINE
}

\begin{abstract}
The aim: To determine a possible role of nitric oxide system as one of the pathogenesis links in Stevens-Johnson syndrome depending on the severity of disease progression. Material and methods: We examined 11 patients with Stevens-Johnson syndrome. The function of nitric oxide system (NO - NOS) in blood serum was examined. Results: During the study of nitric oxide system (NO-NOS) in patients with SJS, it was observed that $\mathrm{NO}_{2}{ }^{-}$level was increased by 1.53 times, $\mathrm{NO}_{3}{ }^{-}$level - by 3.33 times, activity of total NOS - by 5.78 times, constitutive (CNOS) - by 1.81 times and inducible (iNOS) - by 13.36 times.

Conclusions: The intensity of nitric oxide system function was studied in patients with Stevens-Johnson syndrome and dependence of changes of its parameters from the clinical signs of disease was detected. It was found that the determination of nitrite and nitrate anion levels in blood serum can be used for the purpose of predicting the disease course and choosing the therapy methods for the patients with SJS.
\end{abstract}

KEY WORDS: allergy, medications, Stevens-Johnson syndrome, nitric oxide system

Wiad Lek. 2020;73(9 p. II):1900-1903

\section{INTRODUCTION}

More and more frequently, the diseases that constitute a group of severe toxic and allergic skin conditions, Stevens-Johnson syndrome (SJS), are diagnosed by dermatovenerologists in their everyday practice [1]. An increased incidence of diseases of this nosology is the result of the increase in the number of medications available in the pharmaceutical market, which leads to mass self-medication of population [2]. Today patients tend to seek medical treatment after self-medication, when they have already taken medicines of different pharmacological groups, and thus doctors observe either sustained form of dermatosis or development of drug allergy.

Drug allergy can also be triggered by conditions associated with the effect of adverse environmental factors on the body, genetic predisposition, general allergization of the body, unsafe work environment, chronic diseases, etc. as well as often unjustified prescription of multiple medicines taken simultaneously when conducting complex medicamentous therapy $[3,4,5]$.

Drug allergy clinical signs may include [6]: hives, angioedema, unclassified exanthems, fixed drug eruption, drug-induced vasculitis, erythema multiforme (at moderate allergy symptoms), anaphylactic shock, Stevens-Johnson syndrome and Lyell's syndrome or toxic epidermal necrolysis (at severe drug allergy symptoms) [2,7].

Stevens-Johnson syndrome is a severe toxic and allergic skin reaction, often fatal, which is characterized by acute onset, fever, bullous eruption and large blisters on the swol- len and hyperemic mucous membrane of the oral cavity, pharynx, tongue, tonsils, gums, which later burst, merge and get grey coating. Apart from the mucous membrane, which is predominantly affected in SJS, erythematous, vesicular and papular eruption appears on the face, torso and limbs $[8,9]$. The following degrees of severity in the course of SJS are distinguished: mild (mild lesion of oral mucosa, single erythematous eruption on the torso and limbs), moderate (low-grade fever, lesion of oral mucosa, small blisters on erythematous background) and severe (fever, lesion of mucous membranes of both mouth and reproductive organs, massive bullous eruption on erythematous background, skin lesion up to 10\%). In 50\% of cases, SJS is triggered by medicines, in other cases it is caused by the infectious agents etc. $[10,11]$. SJS pathogenesis has not been fully studied. The disease is considered as a hyperergic reaction, which affects keratinocytes and is triggered by infection, medications and toxic agents $[12,13]$. The effect on keratinocytes can be conditioned by all four types of inflammation according to immune system classification, however the most significant are of the 3-4th types. The mortality rate in SJS is from 5 to $10 \%$ of the cases $[14,15]$.

Nitric oxide (NO), which is synthesized in the body, is a unique intra- and extracellular messenger that mediates neurotransmission, cell cooperation, vasodilation, immune response, etc. The synthesis of NO from L-Arginine is carried out by three main NOS isoforms, in particular: two constitutive synthases (cNOS) (neuronal and endothelial) and one inducible NO synthase (iNOS). An increased or 
Table I. $\mathrm{NO}_{2}, \mathrm{NO}_{3}$ content, $\mathrm{NO}$ synthases activity $(\mathrm{M} \pm \mathrm{m})$ in the blood serum of patients with Stevens-Johnson syndrome

\begin{tabular}{ccc}
\hline $\begin{array}{c}\text { Indicator, } \\
\boldsymbol{\mu m o l} / \mathrm{I}\end{array}$ & $\begin{array}{c}\text { Patients with SJS, } \\
\mathbf{n = 1 1}\end{array}$ & $\begin{array}{c}\text { Control group, } \\
\mathbf{n}=\mathbf{2 0}\end{array}$ \\
\hline $\mathrm{NO}_{2}{ }^{-}, \mu \mathrm{mol} / \mathrm{I}$ & $6.82 \pm 0.41^{*}$ & $4.45 \pm 0.19$ \\
\hline $\mathrm{NO}_{3}{ }^{-}, \mu \mathrm{mol} / \mathrm{I}$ & $10.93 \pm 1.14^{*}$ & $3.28 \pm 0.14$ \\
\hline $\mathrm{NO}_{2}{ }^{-} / \mathrm{NO}_{3}{ }^{-}$ & $0.62 \pm 0.05^{*}$ & $1.36 \pm 0.07$ \\
\hline Total NOS, $\mathrm{nmol} / \mathrm{min} \cdot \mathrm{I}$ & $1.85 \pm 0.25^{* *}$ & $0.32 \pm 0,05$ \\
\hline $\mathrm{cNOS}, \mathrm{nmol} / \mathrm{min} \cdot \mathrm{I}$ & $0.38 \pm 0.07^{*}$ & $0,21 \pm 0.03$ \\
\hline iNOS, nmol/min.l & $1.47 \pm 0.19^{* *}$ & $0.11 \pm 0.02$ \\
\hline $\mathrm{cNOS} / \mathrm{iNOS}$ & $0.26 \pm 0.05^{* *}$ & $1.91 \pm 0.22$ \\
\hline
\end{tabular}

Note: Significant difference between the indicators in patients and control group individuals by $p<0.05^{-*}, p<0.01^{-* *}$.

Table II. $\mathrm{NO}_{2}{ }^{-}, \mathrm{NO}_{3}{ }^{-}$content, $\mathrm{NO}$ synthases activity $(\mathrm{M} \pm \mathrm{m})$ in the blood serum of patients depending on Stevens-Johnson syndrome severity

\begin{tabular}{ccc}
\hline \multirow{2}{*}{ Indicator } & \multicolumn{2}{c}{ Patients with different SJS severity } \\
\cline { 2 - 3 } & $\begin{array}{c}\text { mild and moderate, } \\
\mathbf{n}=\mathbf{6}\end{array}$ & $\begin{array}{c}\text { severe, } \\
\mathbf{n}=\mathbf{5}\end{array}$ \\
\hline $\mathrm{NO}_{2}^{-}, \mu \mathrm{mol} / \mathrm{I}$ & $7.46 \pm 0.52^{* *}$ & $5.59 \pm 0.37$ \\
\hline $\mathrm{NO}_{3}^{-}, \mu \mathrm{mol} / \mathrm{l}$ & $8.38 \pm 1.03^{*}$ & $12.06 \pm 1.25^{* *}$ \\
\hline $\mathrm{NO}_{2}{ }^{-} / \mathrm{NO}_{3}^{-}$ & $0.89 \pm 0.07^{*}$ & $0.46 \pm 0.03^{* *}$ \\
\hline Total NOS, $\mathrm{nmol} / \mathrm{min} \cdot \mathrm{I}$ & $1.49 \pm 0.14^{* *}$ & $2.09 \pm 0.28^{* *}$ \\
\hline $\mathrm{cNOS}, \mathrm{nmol} / \mathrm{min} \cdot \mathrm{I}$ & $0.33 \pm 0.05$ & $0.39 \pm 0.08^{*}$ \\
\hline iNOS, $\mathrm{nmol} / \mathrm{min} \cdot \mathrm{l}$ & $1.16 \pm 0.10^{* *}$ & $1.70 \pm 0.21^{* *}$ \\
\hline $\mathrm{cNOS} / \mathrm{iNOS}$ & $0.28 \pm 0.06^{* *}$ & $0.23 \pm 0.03^{* *}$
\end{tabular}

Note: Significant difference between the indicators in patients and contro group individuals by $\mathrm{p}<0.05-{ }^{*}, \mathrm{p}<0.01-{ }^{* *}$.

decreased production of $\mathrm{NO}$ and its metabolites in the body is one of the factors of the regulation of physiological functions as well as pathogenesis of pathological conditions [16].

Both an insufficient and excessive production of $\mathrm{NO}$ triggers pathophysiological reactions, which are formed in tissues and play a significant role in pathogenesis of different inflammatory conditions, arterial hypertension, pulmonary hypertension, diabetic angiopathy, thrombosis, as well as skin conditions, neurological and digestive disorders, etc. [17]. An excessive NO production due to NOS induction is an important factor of general and local hemodynamic and other disorders. The activation of NO synthesis is typical of shocks of different nature - heat, septic, cardiogenic, anaphylactic and hemorrhagic ones. Deficiency of NO, which is connected with its insufficient production and accelerated decomposition, determines disadaptation to hypoxia of different nature, immunopathological reactions and endothelial dysfunction $[18,19]$.

A wide spectrum of bioregulatory effect of NO, in particular, its involvement in the course of allergic inflammation (cytotoxic, immune complex-mediated reactions), regulation of vascular tone and coagulation, cell proliferation, etc., suggests an involvement of NO in SJS pathogenesis and allows for a study of the condition of NO - NOS system in patients, taking into consideration lack of information on this issue in the available literature sources.

\section{THE AIM}

The aim of our study was to define a possible role of nitric oxide system as one of the pathogenesis links in Stevens-Johnson syndrome by determining the content of stable metabolites of nitrite and nitrate anions, constitutive (cNOS) and inducible NOS (iNOS) in the blood serum of patients in case monitoring.

\section{MATERIAL AND METHODS}

We examined 11 patients with Stevens-Johnson syndrome (range 30-49 years, 6 men and 5 women). The levels of the disease severity were different in the patients under examination (mild and moderate in 6 individuals and severe in 5 individuals). A control group consisted of 20 apparently healthy individuals.

The analysis of the NO - NOS system function was made in the blood serum of 11 patients with SJS. The concentration of nitrate anion $\left(\mathrm{NO}_{2}^{-}\right)$was measured by spectrophotometric method using a standard Griess reagent [20]. The level of nitrate anion $\left(\mathrm{NO}_{3}{ }^{-}\right)$was determined by means of brucine reagent [21].

The activity of total NOS $\left(\mathrm{Ca}^{2+}\right.$ dependent and $\mathrm{Ca}^{2+}$ independent) was studied by using a classical method adjusted to the spectrophotometric measurement of one of the reaction products - nitrite anion [22]. Total NOS was examined first and then $\mathrm{Ca}^{2+}$ independent iNOS (by adding EDTA) was measured. The content of cNOS was calculated by subtracting iNOS concentration from the level of total NOS.

\section{RESULTS AND DISCUSSION}

The bioregulatory effect of NO, its involvement in the course of allergic inflammation, regulation of vascular tone and coagulation, cell proliferation, etc., suggests an involvement of NO in SJS pathogenesis $[16,17,18,23,24]$.

A significant increase in the level of nitrite anions $(\mathrm{p}<0.05)$ and nitrate anions $(\mathrm{p}<0.01)$ was found in the blood serum of patients with SJS, at that, their ratio was sharply decreasing $(\mathrm{p}<0.01)$ compared to the similar parameters in healthy individuals (Table I). The activity of total NOS as well as constitutive and inducible forms significantly exceeded the same in the control group individuals, and the activity of iNOS was especially increasing in SJS $(\mathrm{p}<0.01)$. The cNOS/ iNOS ratio in patients proved to be significantly lower in comparison with the control group $(\mathrm{p}<0.01)$.

A significant increase in $\mathrm{NO}_{2}{ }^{-}$and $\mathrm{NO}_{3}{ }^{-}$content and in total and INOS activity was observed at mild and moderate severity of SJS, whereas at severe skin condition an increase in the level of nitrate anions, total NOS and its isoforms was observed with respect to the same in healthy individuals $(\mathrm{p}<0.05-0.01)$ (Table II). 
Comparison of the indicators in patients with different severity of disease allowed detecting significant increase in nitrite anion content and decrease in nitrate anion level in patients with mild and moderate cases as compared to same in severe SJS $(\mathrm{p}<0.05)$.

Thus, the study of the indicators of NO-NOS system in patients with Stevens-Johnson syndrome showed the intensification of oxidative L-Arginine metabolism, expressed in different quantitative degree in SJS. The activity of total NOS was also maximal in patients with SJS - by 5.78 times. A significant increase in cNOS was observed in patients with SJS (by 1.81 times).

\section{CONCLUSIONS}

During the study, the intensity of nitric oxide system (NONOS) function was analysed and dependence of changes of its parameters from the clinical signs of Stevens-Johnson syndrome was detected. It was found that determination of nitrite and nitrate anion levels in blood serum can be used for the purpose of predicting the disease course and choosing the therapy methods for the patients with SJS.

Thus, it is feasible to combine complex therapy of patients with SJS with medications for the purpose of normalizing NOS isoforms activity and excessive production of nitric oxide (NO).

\section{REFERENCES}

1. Kaliuzhnaia L.D., Turyk L.D. Stevens-Johnson syndrome in a patient with severe relapsing course of the subcorneal pustular dermatosis (SneddonWilkinson disease). Ukrainian Journal of Dermatology, Venereology and Cosmetology. 2017; 3: 91-96.

2. Uts S.R., Bakulev A.L., Morrison A.V. et al. A clinical case of StevensJohnson syndrome in a patient with pustular psoriasis. Saratov Scientific and Medical Journal. 2017; 13(3): 646-648.

3. Melikian A.L., Subortseva I.N., Kovrigina A.M. et al. Stevens-Johnson syndrome after Rituximab treatment in a patient with the small lymphocytic B-cell lymphoma, autoimmune hemolytic anemia and antiphospholipid syndrome. Clinical Oncohematology. Fundamental Research and Clinical Practice. 2017; 10(1): 120-127.

4. Lepehova A.A., Allenova A.S., Olisova 0.Yu. et al. Comparative evaluation of the efficiency of different methods of treatment of Stevens-Johnson syndrome and toxic epidermal necrolysis based on the literature data. Bulletin of Russian Academy of Medical Sciences. 2019; 74(3): 157-166.

5. Lerch M., Mainetti C., Beretta-Piccoli Terziroli B. et al. Current Perspectives on Stevens-Johnson Syndrome and Toxic Epidermal Necrolysis Clin Rev. Allergy Immunol. 2018; 54(1): 147-176. doi: 10.1007/s12016-0178654-z.

6. Wong A., Malvestiti A.A., Hafner M. Stevens-Johnson syndrome and toxic epidermal necrolysis: a review. Rev Assoc Med Bras. 2016; 62 (5): P. 468-73. doi: 10.1590/1806-9282.62.05.468.

7. Alerhand S., Cassella C., Koyfman A. Stevens-Johnson Syndrome and Toxic Epidermal Necrolysis in the Pediatric Population: A Review. Pediatr Emerg Care.2016;32(7): 472-6. doi: 10.1097/PEC.0000000000000840.

8. Holubtsova 0.I., Andreeva N.P., Petrova T.I. et al. Clinical observation of Stevens-Johnson syndrome against a background of severe pneumonia. Practical Medicine. 2016; 3 (95): 92-94.

9. Ergen E.N., Hughey L.C. Stevens-Johnson Syndrome and Toxic Epidermal Necrolysis. JAMA Dermatol. 2017; 153 (12): 1344. doi: 10.1001/ jamadermatol.2017.3957.
10. Das A., Banerjee A., Tripathy K. Topical moxifloxacin-induced StevensJohnson syndrome. J. Cataract Refract Surg. 2017; 43 (6): 860-861. doi: 10.1016/j.jcrs.2017.03.043.

11. Canavan T. N., Mathes E. F. Frieden I. et al. Shinkai Mycoplasma pneumoniae-induced rash and mucositis as a syndrome distinct from Stevens-Johnson syndrome and erythema multiforme: a systematic review. J Am Acad Dermatol. 2015; 72 (2): 239-45. doi: 10.1016/j. jaad.2014.06.026.

12. Saeed H.N.Chodosh J. Ocular manifestations of Stevens-Johnson syndrome and their management. Curr Opin Ophthalmol. 2016; 27 (6): 522-529.

13. Miliszewski M.A., Kirchhof M.G., Sikora S. et al. Stevens-Johnson Syndrome and Toxic Epidermal Necrolysis: An Analysis of Triggers and Implications for Improving Prevention. Am J Med. 2016; 129 (11): 1221-1225. doi:10.1016/j.amjmed.2016.03.022.

14. Dodiuk-Gad R. P., Chung W. H., Valeyrie-Allanore L. et al. StevensJohnson Syndrome and Toxic Epidermal Necrolysis: An Update. Am J Clin Dermatol. 2015; 16 (6): 475-93. doi: 10.1007/s40257-015-0158-0.

15. ZimmermannS., Sekula P.,VenhoffM. et al.Systemic Immunomodulating Therapies for Stevens-Johnson Syndrome and Toxic Epidermal Necrolysis: A Systematic Review and Meta-analysis. JAMA Dermatol. 2017; 153 (6): 514-522. doi: 10.1001/jamadermatol.2016.5668.

16. Nakaki T. Physiological and clinical significance of NO (nitric oxide) - a review. Keio. J. Med. 1997; 43(5): 15-26.

17. Tsukanva H., Miuca M., Tshushida S. Effect of NOS inhibitors on bone metabolism in growing rats. AMER. J. Physiol. 1996; 270 (3): 840-845.

18. Markov H.M., Nadirashvili S.A. On regulation of cardiac activity using L-arginine-nitric oxide system. Problems of Physiology and Experimental Therapy. 2003; 4: 9-13.

19. Gaboury J., Woodman R.C., Gronder D.M. Nitric oxide prevents leukocyte adherence: role of superoxide. Amer. J. Physiol. 1998; 270(3): 862-867.

20. Green L.C. David A.W., Glogowski J. Analysis of nitrate, nitrite, and [15N] nitrate in biological fluids. Anal. Biochem. 1982; 126 (1): 131-138.

21. Vanin A.F. The role of nitric oxide in biomedical studies. Bulletin of Russian Academy of Medical Sciences. 2000; 4: 3-5.

22. Selter M. Knowles K., Moncada S. Widespread tissue distribution, species and changes in activity of $\mathrm{Ca}_{2}+$-dependent and $\mathrm{Ca} 2+$-independent nitric oxide synthase. FEBS Lett. 1997; 295 (2): 145-149.

23. Fatenkov 0.V., Kuzmina T.M., Rubanenko 0.A. et al. Correction of adverse reaction to antibiotics treatment of Stevens-Johnson syndrome. Russian Journal of Allergy. 2015; 6: 68-71.

24. Schneider J.A., Cohen P.R. Stevens-Johnson Syndrome and Toxic Epidermal Necrolysis: A Concise Review with a Comprehensive Summary of Therapeutic Interventions Emphasizing Supportive Measures. Adv Ther. 2017; 34 (6):1235-1244. doi: 10.1007/s12325-017-0530-y.

\section{Scietific research work}

State registration number: 0116 U004506

Cipher: IH. 25. 01.0001. 16

Clinical and experimental justification of monitoring of diagnostics and standardized methods for treatment of metabolic disorders of internal organs and skin and their complications.

\section{ORCID and contributionship:}

Natalya V. Ivanyushko - Nazarko: 0000-0001-7524-9247 ${ }^{\text {A,B,C,D,E,F }}$

Orysya O. Syzon: 0000-0002-7011-2521 ${ }^{A, D, E, F}$

Svitlana V. Volbyn: 0000-0002-5066-3951 A,E

Tetyana I. Rudnyk: 0000-0002-4019-567X ${ }^{A, B}$

Marianna O. Dashko: 0000-0001-6441-5326 D,E,F 


\section{Conflict of interest:}

The Authors declare no conflict of interest.

\section{CORRESPONDING AUTHOR}

\section{Marianna 0. Dashko}

Danylo Halytsky Lviv National Medical University

1 Konovalets str., 79014 Lviv, Ukraine

tel: +380677691977; +380504131489

e-mail:mariannadashko@gmail.com

Received: 14.03 .2020

Accepted: 03.07.2020

\footnotetext{
A - Work concept and design, B - Data collection and analysis, $\mathbf{C}-$ Responsibility for statistical analysis,

D-Writing the article, $\mathbf{E}-$ Critical review, $\mathbf{F}$ - Final approval of the article
} 